\title{
Gaseous and Particulate Exhaust Emissions of Hybrid and Conventional Cars over Legislative and Real Driving Cycles
}

\author{
Maria Antonietta Costagliola1, Maria Vittoria Prati1 ${ }^{*}$, Antonio Mariani2 ${ }^{2}$ Andrea Unich², \\ Biagio Morrone ${ }^{2}$ \\ ${ }^{1}$ Istituto Motori, National Research Council, Napoli, Italy \\ ${ }^{2}$ Department of Industrial and Information Engineering, Second University of Naples, Aversa (CE), Italy \\ Email: ${ }^{*}$ m.v.prati@im.cnr.it
}

Received 6 March 2015; accepted 1 May 2015; published 6 May 2015

Copyright (C) 2015 by authors and Scientific Research Publishing Inc.

This work is licensed under the Creative Commons Attribution International License (CC BY). http://creativecommons.org/licenses/by/4.0/

(c) †) Open Access

\begin{abstract}
Road transport exhaust emissions represent the main sources of atmospheric pollution in urban areas, due to the growing number of circulating vehicles and travelled distances. In order to reduce this pollution source, stricter emission standards are periodically set by governments throughout the world. Consequently, the concentrations of gaseous pollutants and particulate mass to be measured during type-approval tests of new vehicles are becoming progressively lower; moreover from 2011, diesel cars have to comply with particle number limit. In order to assess emission levels of different technology vehicles and investigate the use of a particulate number measurement technique at the exhaust of very low-emitting vehicles, an experimental activity was carried out on three in-use vehicles: a diesel car equipped with a particulate trap (DPF), a hybrid gasoline-electric car and a bi-fuel passenger car fuelled with compressed natural gas (CNG). Cold and hot gaseous and particulate emission factors and fuel consumption were measured during the execution of real and regulatory driving cycles on a chassis dynamometer. Particulate was characterized in terms of mass only for the diesel car and of particle number for all vehicles. The emissions measured over the NEDC show that all three vehicles comply with their standard limits, except CO for CNG passenger car and NOx for diesel car. Cold start influences $\mathrm{CO}$ and $\mathrm{HC}$ emissions and fuel consumption for all the tested vehicles and in particular for the hybrid car. The real driving cycle is the most critical pattern for the emissions of almost all pollutants. During constant speed tests, the emissions of particles of hybrid car are an order of magnitude lower than those of the CNG car.
\end{abstract}

\footnotetext{
${ }^{*}$ Corresponding author.
}

How to cite this paper: Costagliola, M.A., Prati, M.V., Mariani, A., Unich, A. and Morrone, B. (2015) Gaseous and Particulate Exhaust Emissions of Hybrid and Conventional Cars over Legislative and Real Driving Cycles. Energy and Power Engineering, 7, 181-192. http://dx.doi.org/10.4236/epe.2015.75018 


\section{Keywords}

\section{Particulate, Vehicle Emissions, Hybrid Car, Natural Gas, DPF}

\section{Introduction}

Despite technological improvements in internal combustion engines, fuels and after-treatment devices, pollutant emissions by on-road transport are still responsible for high levels of air pollution in urban areas due to the growing number of circulating vehicles as well as the length and number of trips undertaken. In recent years particulate emissions have given rise to particular concern due to their detrimental effects on human breathing apparatus and environmental health. The harmful potential of particulate related to its size and chemical composition have been amply demonstrated [1] and the International Agency for Research on Cancer (IARC), the specialized cancer agency of the World Health Organization, announced in 2013 that particulate matter, a major component of outdoor air pollution, was classified as carcinogenic to humans (Group 1) [2]. Smaller particles are able to penetrate more deeply into human lungs and particles emitted at the vehicle exhaust mainly consist of a carbonaceous fraction with condensed organics including carcinogenic substances such as aromatics.

The US National Ambient Air Quality Standards (NAAQS) for PM10/PM2.5 are more protective than European ambient air standards, while the EU has the most stringent engine and vehicle emission standards for particulates. The European Community has introduced the limit of $6 \times 10^{11}$ particles $/ \mathrm{km}$ for the diesel vehicles (Euro 5b stage from 2011) and for Gasoline Direct Injection (GDI) spark ignition engines (Euro 6 stage from 2014), by regulating also the sampling and measuring protocol) [3] [4]. Up to 2017, the limit for GDI vehicles is increased of one order of magnitude $\left(6 \times 10^{12}\right.$ particles $\left./ \mathrm{km}\right)$.

Diesel Particulate Filter (DPF) has proved to be the most efficient device for particulate reduction at the compression ignition vehicle exhaust. The filtration efficiency of a catalyzed DPF is about 99\% [5] [6], but extraemissions during regeneration mode could affect the emission factors of vehicles equipped with DPF [7].

Besides the need to reduce harmful exhaust emissions, the objective of European transport policy is to promote the purchase of fuel-efficient vehicles (FEVs), as a strategy to reduce carbon dioxide emissions in the atmosphere which represents a major greenhouse gas (GHG). The European agreement for GHG emissions states a fleet-average $\mathrm{CO}_{2}$ emission target of $130 \mathrm{~g} / \mathrm{km}$ which must be reached by each vehicle manufacturer by 2015 . Moreover, a fleet-average $\mathrm{CO}_{2}$ emission target of $95 \mathrm{~g} / \mathrm{km}$ must be met by each manufacturers' new passenger cars registered in 2020. Among FEVs a decisive role is played by hybrid technology whose market share in the EU keeps increasing and reached a level of $1.4 \%$ of all new car sales in 2013. The number is still relatively low, but more than twice as high as two years ago [8]. The fuel saving of hybrid vehicles was assessed in several research papers [9] [10].

According to Samaras and Meisterling, plug-in hybrid electric vehicles (PHEVs) reduce life cycle GHG emissions by $32 \%$ compared to conventional vehicles but have small reductions compared to traditional hybrids [11].

The use of compressed natural gas (CNG) in place of gasoline as fuel for spark ignition engines should produces, in general, smaller quantities of carbon dioxide and other pollutants per unit of power generated [12] [13]. Despite this general assessment, results from previous studies are not so optimistic. In some cases, conversion from gasoline to CNG might increase certain pollutants such as particle number [14] [15]. Moreover, the major constituent of unburned emissions is methane which is a more powerful GHG than carbon dioxide and is also one of the most difficult hydrocarbon to be oxidized over the three-way catalyst [16] [17].

The aim of this paper is to assess emission levels of some in-use vehicles of different technology. For these purpose, an experimental campaign was carried out for measuring gaseous and particulate emissions at the exhaust of a gasoline-electric hybrid car, a bi-fuel gasoline/natural gas vehicle and a diesel car equipped with a particulate filter (DPF), all of them homologated to Euro 4 standard. The vehicles were tested on a chassis dynamometer during driving cycles (both type-approval and real ones) and steady state tests for computing emission factors of carbon monoxide, hydrocarbons, nitrogen oxides, carbon dioxide and particulate, characterized as total number of particles and size distribution. 


\section{Experimental Set-Up}

\subsection{Vehicles}

The tested vehicles were a gasoline-electric hybrid passenger car, a bi-fuel gasoline/natural gas (CNG) passenger car fuelled with CNG during the experimental tests and a diesel car equipped with a particulate filter (DPF). The main characteristics of these vehicles are given in Table 1.

These in-use vehicles were approved according to Euro 4 legislative standards. The hybrid vehicle is equipped with a parallel hybrid configuration, with the electric motor that assists the gasoline engine during starting and acceleration phases; when slowing down or braking, energy is also recovered by the same motor serving as a generator. This system incorporates an idle-stop feature that shuts off the engine at traffic lights. This model of car is classified as a mild hybrid vehicle. The natural gas (CNG) vehicle is a commercial bi-fuel gasoline/CNG passenger car. It is equipped with a three-way catalyst for pollutants abatement during both fueling modes and the CNG injection system is tuned to operate in stoichiometric condition by using the lambda sensor for the air/ fuel ratio measurement. Both these vehicles utilize Port Fuel Injection (PFI) where the fuel is sprayed into the intake port. The diesel car is equipped with a DPF system positioned downstream of an oxidation catalyst.

\subsection{Driving Cycles}

Emission factors were measured over the type-approval New European Driving Cycle (NEDC). The entire cycle includes the Urban Driving Cycle (UDC) consisting of four repetitions of the same module, and an Extra-Urban segment (EUDC) (Figure 1(a)).

It was driven in cold start condition as prescribed by European legislation. In order to characterize emission behavior during a more realistic driving pattern, a real world driving cycle, called Artemis Urban, was also performed. The Artemis Urban driving cycle was originally designed by INRETS (Institut National de Recherche sur les Transports et leur Sécurité, France) as a real world cycle representing urban congested traffic [18]. It consists of a pre-conditioning phase lasting 72 seconds during which bag sampling is not active, followed by a bag sampling phase lasting until the end of cycle (Figure 1(b)). It was driven in hot starting conditions (i.e. hot conditioned engine fluids) after the execution of a NEDC. The NEDC cycle was repeated three times whereas Artemis Urban was performed once for hybrid and CNG cars and two times for the diesel car. The main kinematic characteristics of the driving cycles are reported in Table 2; it can be observed that the Artemis Urban has more time spent in accelerations and less in cruising than the UDC driving cycle. In the same table also the characteristics of low and medium phases of the new worldwide harmonized Light duty driving Test Cycle (WLTC) are reported for the discussion. The WLTC cycle has been derived from "real world" driving data from different regions (EU + Switzerland, USA, India, Korea and Japan) covering a wide range of vehicle, over different road types and driving conditions [19].

Constant speed tests (30, 70 and $120 \mathrm{~km} / \mathrm{h}$ ) were also performed in order to measure dimensional distribution of particles. Hybrid and CNG cars were driven by an automatic driving system (Horiba-ADS 7000), whereas the diesel car by a human.

Table 1. Vehicle characteristics.

\begin{tabular}{|c|c|c|c|c|c|c|}
\hline Vehicle & Engine type & $\begin{array}{c}\text { Engine } \\
\text { displacement, } \\
\mathrm{cm}^{3}\end{array}$ & Power, kW & $\begin{array}{l}\text { Reference } \\
\text { mass, kg }\end{array}$ & $\begin{array}{c}\text { Emission control } \\
\text { devices }^{\mathrm{a}}\end{array}$ & Transmission \\
\hline Hybrid & $\begin{array}{l}\text { Gasoline engine (multiport } \\
\text { sequential fuel injection) plus } \\
\text { electric engine }\end{array}$ & 1339 & $85(70+15)$ & 1318 & EGR plus TWC & Automatic \\
\hline CNG & $\begin{array}{c}\text { Gasoline-CNG engine, multiport } \\
\text { sequential fuel injection }\end{array}$ & 1242 & 38 & 1050 & TWC & 5-gears manual \\
\hline Diesel & $\begin{array}{l}\text { Electronically controlled direct } \\
\text { injection with common rail, } \\
\text { turbocharger and intercooler }\end{array}$ & 1461 & 76 & 1590 & DOC plus DPF & 6-gears manual \\
\hline
\end{tabular}

${ }^{\mathrm{a} E G R: ~ E x h a u s t ~ G a s ~ R e c i r c u l a t i o n ; ~ T W C: ~ T h r e e ~ W a y ~ C a t a l y s t ; ~ D O C: ~ D i e s e l ~ O x i d a t i o n ~ C a t a l y s t ; ~ D P F: ~ D i e s e l ~ P a r t i c u l a t e ~ F i l t e r . ~}$ 
NEW EUROPEAN DRIVING CYCLE - NEDC

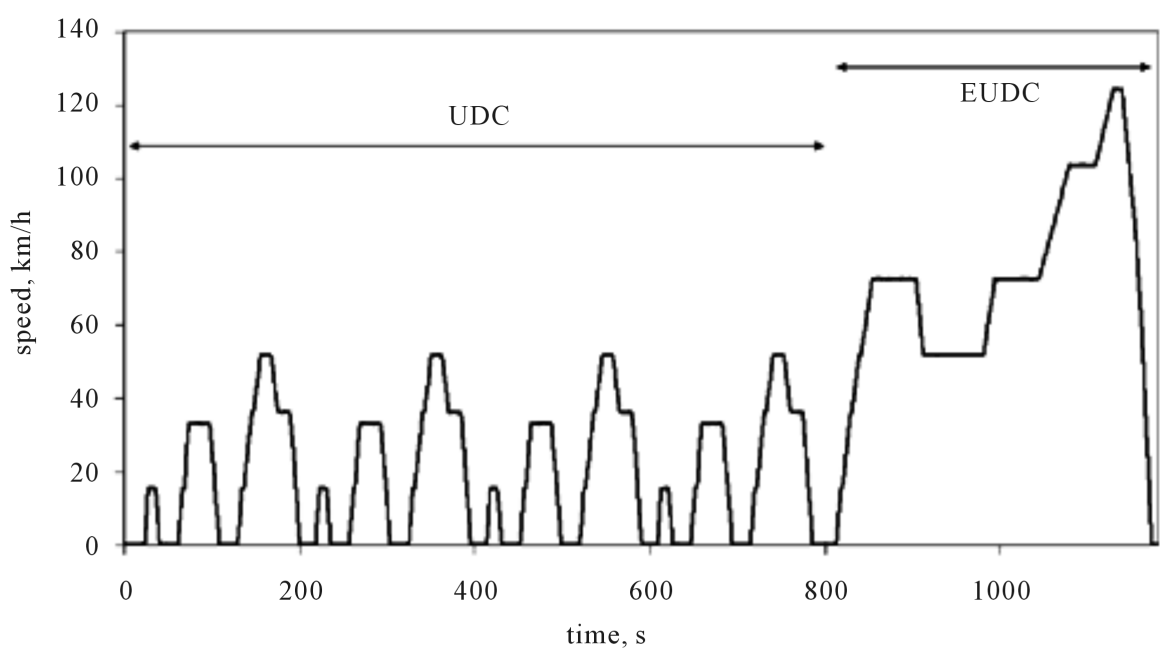

(a)

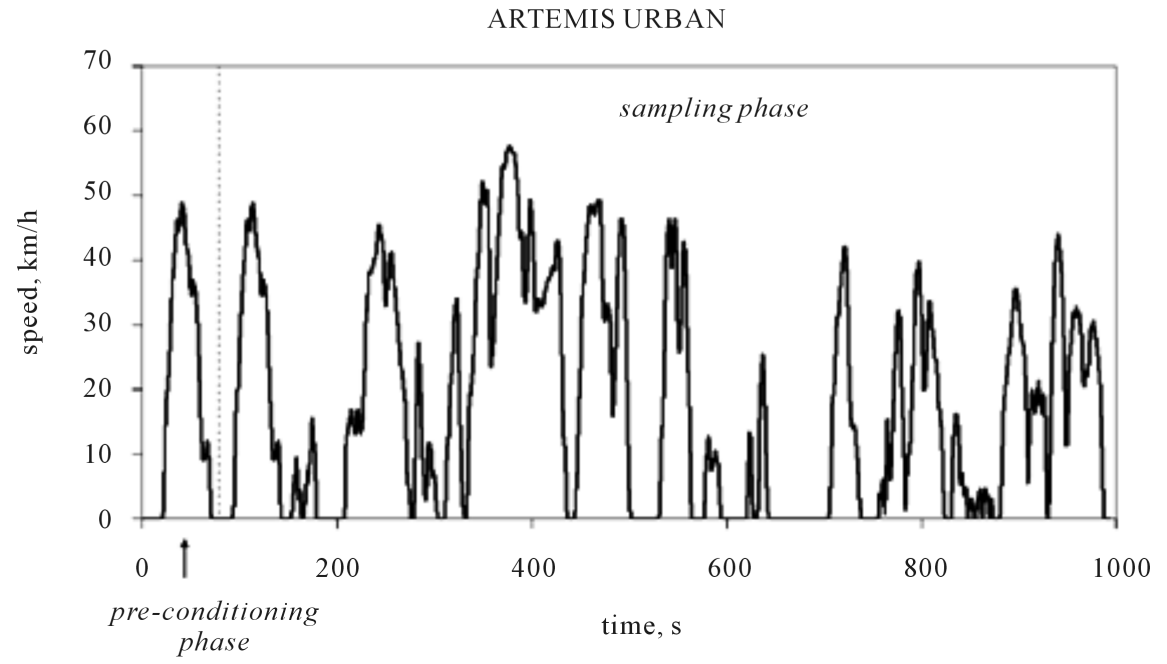

(b)

Figure 1. Speed trace of NEDC and Artemis Urban driving cycles.

Table 2. Characteristics of driving cycles UDC, EUDC, Artemis Urban, WLTC ${ }^{*}$ (only low phase) and WLTC.

\begin{tabular}{lccccc} 
& UDC & EUDC & $\begin{array}{c}\text { Artemis } \\
\text { Urban }\end{array}$ & WLTC low $^{*}$ & WLTC \\
\hline Duration [s] & 780 & 400 & 993 & 589 & 1800 \\
Length [km] & 4.00 & 6.9 & 4.87 & 3.09 & 23.27 \\
Average speed [km/h] & 18.4 & 62.6 & 17.7 & 18.9 & 46.5 \\
Max speed [km/h] & 50 & 120 & 57.3 & 56.5 & 131.3 \\
Idle time [\%] & 23.1 & 8.7 & 20.7 & 15.8 & 12.6 \\
Cruising time [\%] & 25.1 & 49.2 & 9.7 & 28.8 & 25.3 \\
Acceleration time [\%] & 27.2 & 29.8 & 35.9 & & 31.9
\end{tabular}




\subsection{Description of Measurement Set-Up}

Tests were conducted on a Schenck chassis dynamometer connected to a Single-Axle Large Roll with a 1.59 meter (62.6") diameter, which is able to simulate vehicle inertia and vehicle road load power demand as a function of speed. During the execution of a driving cycle, the total exhaust stream is collected and diluted using a positive displacement pump-constant volume sampler (PDP-CVS) dilution system. The dilution air is taken from the test cell and is sent through a high-efficiency particulate air (HEPA) filter for removing the background particulate matter. A proportional stream of diluted exhaust mixture is continuously collected and stored in Tedlar sample bags for the analysis of pollutant average concentration at the end of each driving cycle. A Horiba Mexa $7200 \mathrm{H}$ gas analyzer was utilized to measure diluted exhaust concentrations. Carbon monoxide (CO) and carbon dioxide $\left(\mathrm{CO}_{2}\right)$ were measured by Non-Dispersive InfraRed (NDIR) detector, total unburnt hydrocarbons (THC) by Flame Ionization Detector (FID), nitrogen oxides (NOx) by chemiluminescence detector (CLD) and oxygen $\left(\mathrm{O}_{2}\right)$ by paramagnetic detector. A gravimetric method is used to determine the particulate matter (PM) emission factors of the diesel car tested. An isokinetic particulate sampling system, inserted into the dilution tunnel, directs the exhaust through Pallflex T60A20 $47 \mathrm{~mm}$ filters which collect particulate mass from the sample stream. The difference in filter weight before and after the test gives the total particulate mass emitted during the driving cycle. An Electrical Low Pressure Impactor (ELPI) was used for measuring particle number distribution, over 12 collecting stages, in the range $7 \mathrm{~nm}$ up to $10 \mu \mathrm{m}$. The ELPI was positioned downstream of a further double-stage partial sampling system (Dekati FPS) which operated with a sampling flow rate of 6 liter/min, a dilution factor of about 17 and $150^{\circ} \mathrm{C}$ as primary dilution temperature. The ELPI plus FPS system was positioned at the raw exhaust. Such configuration does not fully comply with the EU Particle Measurement Programme (PMP) protocol [4]. Modal analysis of gas concentrations at the raw exhaust was also performed by using the portable emission measurement system SEMTECH analyzer by Sensors, Inc. This system is equipped with its own exhaust flow meter (EFM) which uses the Pitot tube principle. The scheme of the experimental setup is reported in Figure 2.

\section{Results}

A preliminary analysis was carried out to compare measured emission factors of $\mathrm{CO}, \mathrm{HC}$, NOx and $\mathrm{HC}+\mathrm{NOx}$ with type-approval standard limits from Euro 4 to Euro 6, as reported in Table 3. PM was also measured for the diesel car as prescribed by European legislation. The diesel car NOx emissions are slightly higher than the Euro 4 limit, whereas particle emissions (PN) are more ten times lower than the Euro 4 limit and complies with the Euro 5 and Euro 6 PM and PN standards. Looking at the emissions of the passenger cars, it is evident that only one exceedance was found: $\mathrm{CO}$ emitted by the CNG vehicle is slightly higher than the standard limit.

Figures 3-5 show $\mathrm{CO}, \mathrm{HC}$, NOx, $\mathrm{CO}_{2}$ emission factors and fuel consumption (expressed in $\mathrm{g} / \mathrm{km}$ ), particle number (PN) emission factors (expressed as \#/km) during cold and hot UDC, EUDC and Artemis Urban driving cycles. UDC cold refers to the first two repetitions of the UDC module, whereas UDC hot to the last two ones.

Cold start gives a major contribution to total $\mathrm{CO}$ and $\mathrm{HC}$ emissions for all the tested vehicles (Figure 3). The ratio between UDC cold and UDC cold + hot CO emissions ranges from $93 \%$ of the NG passenger car to $98 \%$ of the hybrid and Diesel vehicles, while for HC ranges from $60 \%$ of the Diesel to $99 \%$ of the spark ignition ve-

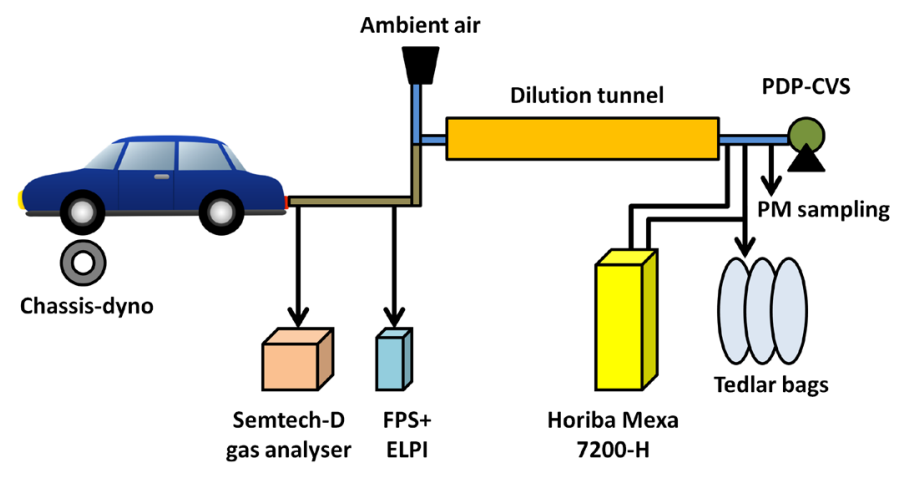

Figure 2. Experimental set-up. 
Table 3. Comparison of emissions with Euro 4 and 5 standard limits.

\begin{tabular}{|c|c|c|c|c|c|c|}
\hline & $\mathrm{CO}, \mathrm{g} / \mathrm{km}$ & $\mathrm{HC}, \mathrm{g} / \mathrm{km}$ & NOx, g/km & $\mathrm{HC}+\mathrm{NOx}, \mathrm{g} / \mathrm{km}$ & $\mathrm{PM}, \mathrm{mg} / \mathrm{km}$ & $\mathrm{PN}, \# / \mathrm{km}$ \\
\hline Diesel car with DPF & 0.10 & 0.010 & $\underline{0.253}$ & 0.263 & 1.9 & $3.6 \times 10^{10}$ \\
\hline Euro 4 standard limit & 0.5 & & 0.25 & 0.30 & 25 & \\
\hline Euro 5 standard limit & 0.5 & & 0.18 & 0.23 & 5 & $6 \times 10^{11}$ (stage b) \\
\hline Euro 6 standard limit & 0.5 & & 0.08 & 0.17 & 5 & $6 \times 10^{11}$ \\
\hline Hybrid vehicle & 0.16 & 0.04 & 0.01 & 0.05 & & $8.9 \times 10^{11}$ \\
\hline CNG vehicle & $\underline{1.03}$ & 0.06 & 0.03 & 0.09 & & $5.0 \times 10^{11}$ \\
\hline Euro 4 standard limit & 1 & 0.1 & 0.08 & & & \\
\hline Euro 5 standard limit & 1 & 0.1 (0.068 NMHC) & 0.06 & & & \\
\hline Euro 6 standard limit & 1 & 0.1 (0.068 NMHC) & 0.06 & & & \\
\hline
\end{tabular}

Underlined values exceed standard limit.
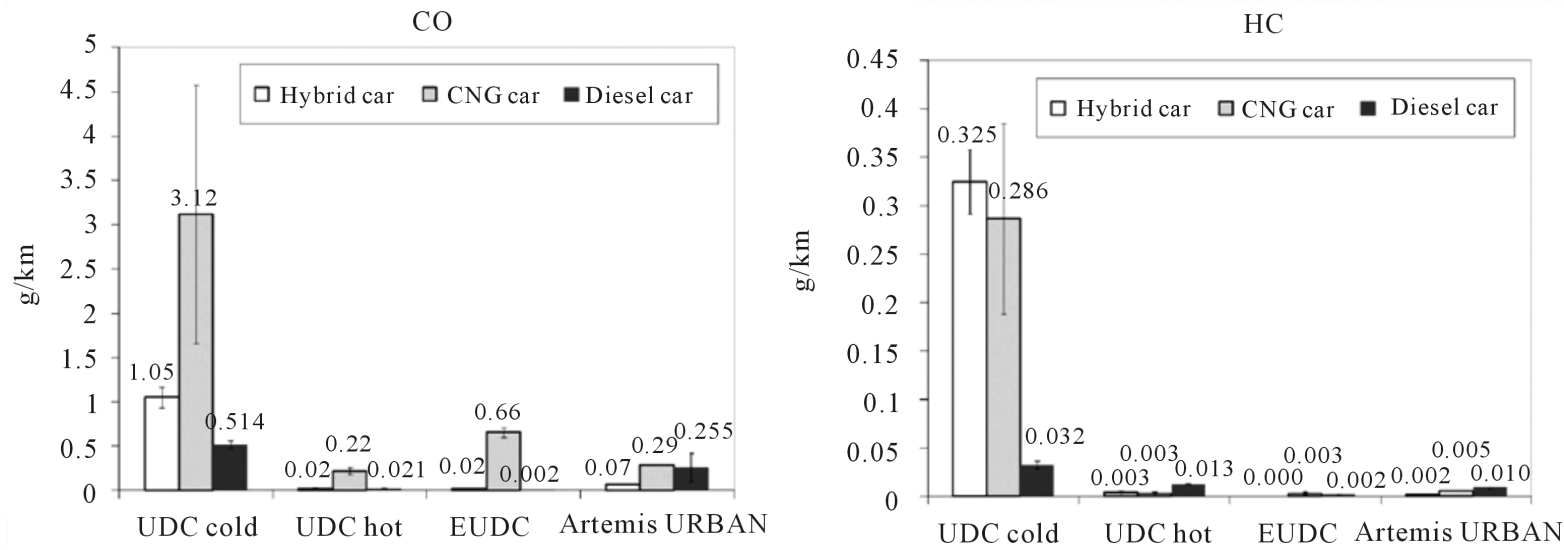

Figure 3. CO and HC emissions during different driving cycles.
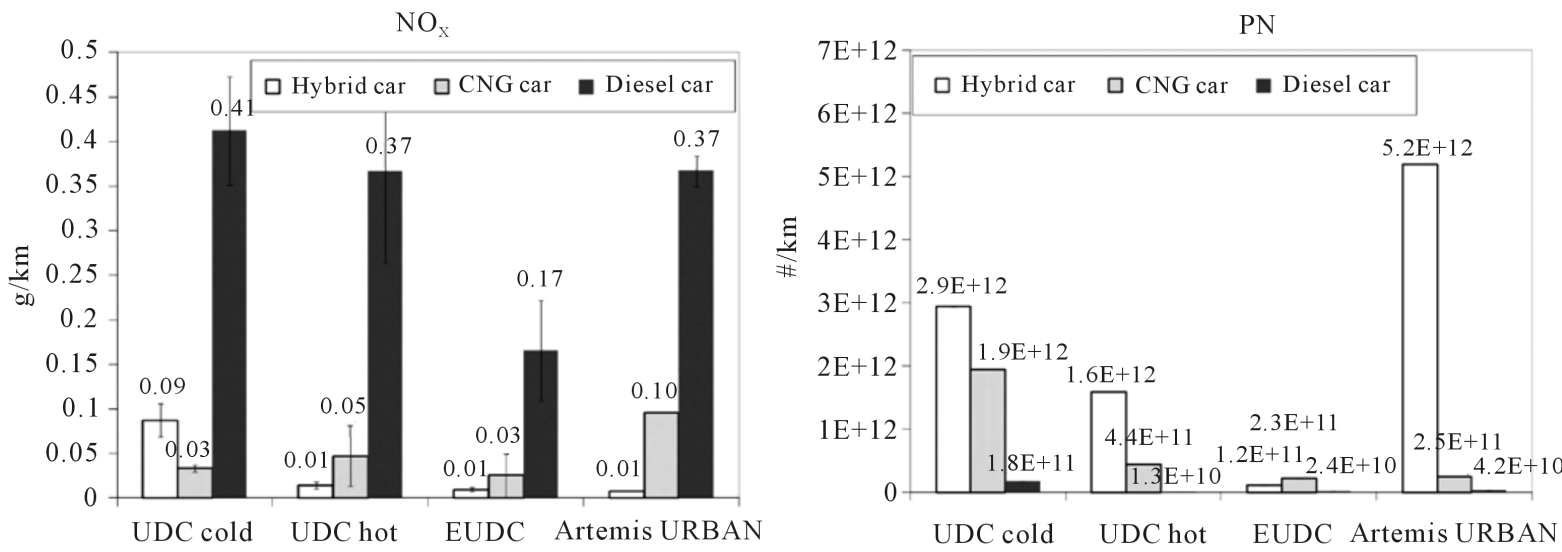

Figure 4. NOx and PN emissions during different driving cycles.

hicles. Such results confirm the strong effect of exhaust after-treatment devices for pollutant abatement of all the tested vehicles once catalyst light-off temperature is reached.

Hot CO emission factors are generally very low over all the tested driving cycles with the exception for the 

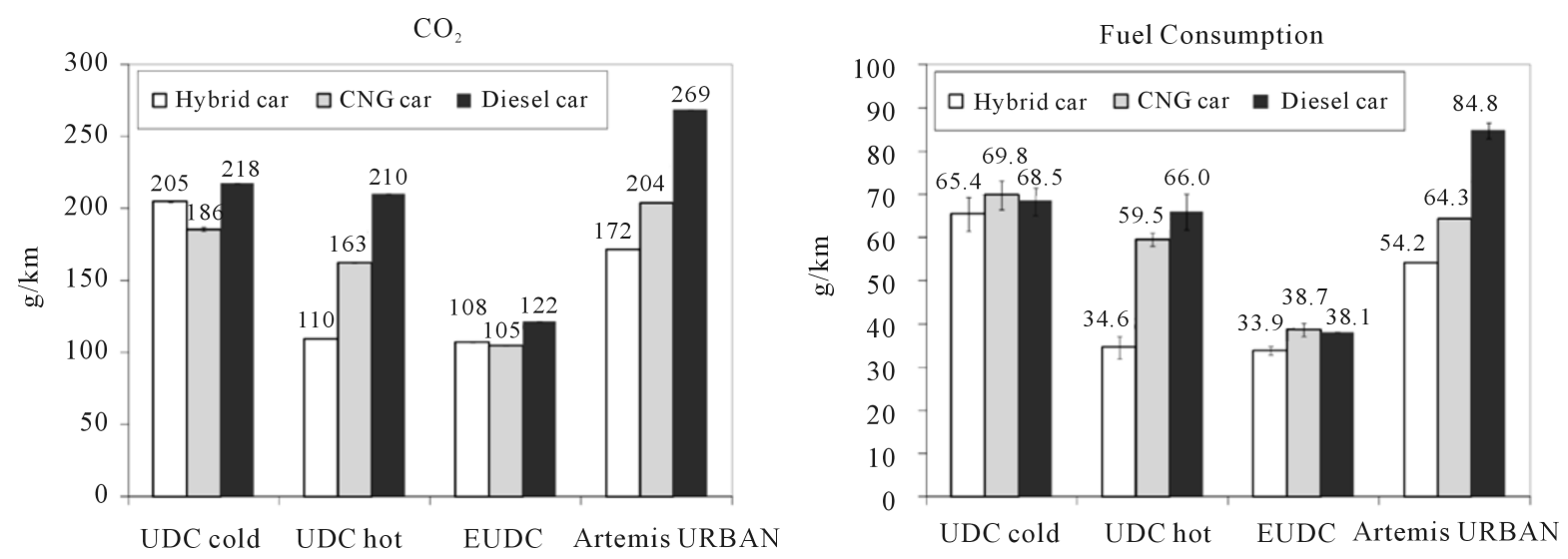

Figure 5. $\mathrm{CO}_{2}$ emissions and fuel consumption during different driving cycles.

CNG vehicle. In this case, CO exhaust emissions appear dependent from vehicle speed: higher speeds involve higher emissions. The same speed dependence was not observed for THC whose exhaust concentration are very close to the background level of the laboratory air.

Cold start has a different effect on NOx emissions of the tested vehicles (Figure 4). In fact cold emissions are much higher than hot one for the hybrid vehicle, because idle stop system does not operate until the thermal engine is warmed up. NOx hot emissions are mildly influenced by the driving cycle. Instead, hot NOx emissions are quite higher than cold one for the CNG vehicle, in particular during the Artemis cycle. Similar hot and cold NOx emissions were measured at the exhaust of the Diesel vehicle [20].

Cold start influences PN emissions, in fact the ratio between UDC cold and UDC cold + hot PN emissions ranges from about $90 \%$ for the diesel and $80 \%$ CNG vehicles to $64 \%$ for the hybrid. During UDC driving cycle the hybrid and the CNG vehicles showed similar PN trends, while PN emissions are much lower for the diesel car. On the Artemis cycle the hybrid vehicle shows PN emissions higher than the CNG one, in agreement with Schreiber et al. [21]. This unexpected result could be due to the frequent engine restart events that could be related to either lower exhaust and catalyst temperatures or "quick start” fuel management strategies [22] [23].

Cold start effect on $\mathrm{CO}_{2}$ emissions was evident on the hybrid vehicle, with a ratio between UDC cold and UDC cold + hot $\mathrm{CO}_{2}$ emission of $65 \%$ (Figure 5), because the idle - stop system operates when the I.C. engine is warmed up. In order to measure the time during which the I.C. engine is turned off, raw concentrations of $\mathrm{O}_{2}$ and $\mathrm{CO}_{2}$ are displayed in Figure 6 during the third module of UDC.

It is evident that the I.C. engine is turned off during idle and cruising phases, when the $\mathrm{O}_{2}$ concentration reaches about $20 \%$ while $\mathrm{CO}_{2}$ and the exhaust flow rate become very low. These data show that, in hot condition, the internal combustion engine is switched off for $45 \%$ of the UDC duration while it never stops during the first UDC module. $\mathrm{CO}_{2}$ emissions on the Artemis Urban driving cycle are higher than those measured on the UDC hot phase of the type-approval cycles: the increase is about 25\% - 27\% for Diesel and CNG car and about 55\% for hybrid car. In particular for hybrid car the I.C.E. is switched off for $15 \%$ of the Urban cycle duration. Obviously similar trends can be observed for fuel consumption.

Constant speed tests at 30, 70 and $120 \mathrm{~km} / \mathrm{h}$ were performed to compare the size distribution of particle emissions in steady state conditions, as reported in Figure 7. The hybrid car emits concentrations of particles ten times lower than those of the CNG car, while the diesel car presents particles number below the detection limit of the instrumentation. The nucleation mode is visible during tests with the CNG car, in agreement with the results of [24]. The large contribution of ultrafine particles with CNG could be explained with the Sulphur (S) content: in fact CNG can contain up to $50 \mathrm{mg} / \mathrm{kg}$ fuel of S, while EU gasoline and diesel fuel less than $10 \mathrm{mg} / \mathrm{kg}$ fuel. Vehicle manufacturers require $10 \mathrm{mg} / \mathrm{m}^{3}$ contaminant cap value which cannot be assured nowadays by the gas industry. The main reason lays on the current odorisation practices, which are typically based on the addition of sulfur-based components to the pipeline, like THT and mercaptanes [25] [26].

CNG and hybrid cars emit more particles at low speed (30 km/h) and less at high speed (120 km/h).

Continuous PN emissions were investigated in depth. Figure 8 reports PN and HC emissions and the contribution of fine particles (aerodynamic diameter $<130 \mathrm{~nm}$ ) to the total particle number during the third module of 


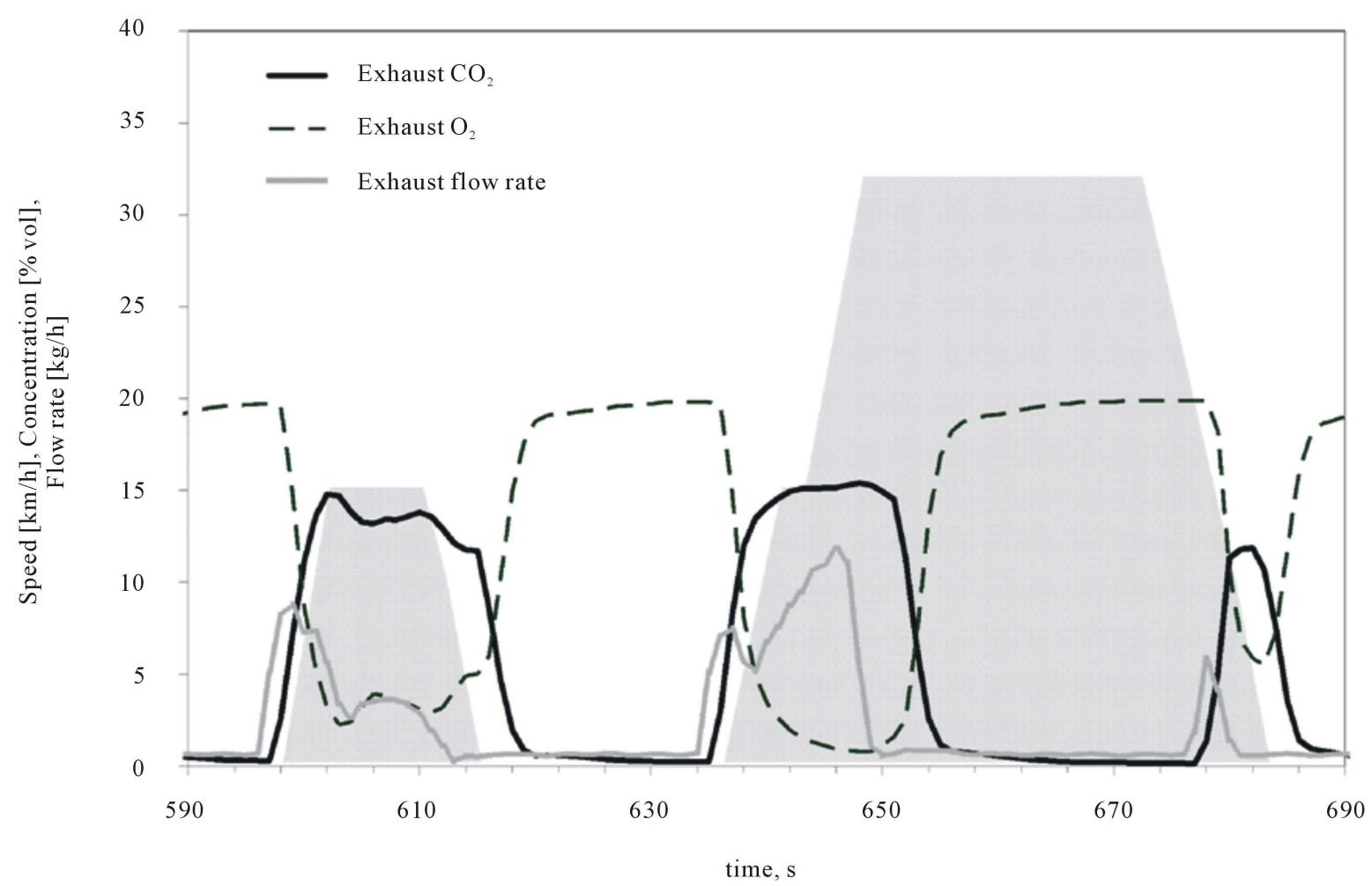

Figure 6. Exhaust flow rate and raw concentrations of $\mathrm{O}_{2}$ and $\mathrm{CO}_{2}$ during the third module of UDC for the hybrid vehicle.

UDC. PN emissions from the hybrid vehicle show some narrow peaks with high values. This behaviour is probably due to engine restart after the idle stops, as previously discussed. Due to the very low HC levels, the contribution of volatiles to total PN cannot be assessed by HC trace. In fact, when comparing the contribution of fine particles with $\mathrm{HC}$ emissions, smaller particles represent all particle number emissions during the majority of driving conditions, even when HC are low. Very different emission behavior was observed at the exhaust of the CNG vehicle. In this case, PN trace seems speed-dependent: this is consistent with the results obtained by Maricq et al. [27] who demonstrated that particulate emissions at the exhaust of spark ignition vehicles occur predominantly during periods of heavy acceleration. The fine particles fraction observed during the same module of driving cycle always covers $90 \%$ - 95\% of total PN, with the exception of the highest speed period, where the fraction of fine particles decreases to $85 \%$ and an increase in particles with an aerodynamic diameter $>300 \mathrm{~nm}$ is found.

It is known that particles in PFI vehicles are mainly produced during rich excursions of the air fuel ratio that occur during cold start and hard accelerations, and generally background levels are released over decelerations and steady speed cruising. In dedicated investigations under steady state conditions, a large vehicle to vehicle variation have been observed in the particulate emissions that could reflect different implementations of the engine control for improved drivability and cold start operation [28]. Diesel PN emissions are the lowest, due to the high trapping efficiency of the DPF, with an evident dependence from vehicle speed. Fine particles account for about $90 \%$ during the whole considered module of UDC. The remaining fraction is made up by particles with a larger aerodynamic diameter between $130 \mathrm{~nm}$ and $1 \mu \mathrm{m}$.

\section{Summary and Conclusion}

Experiments were carried out on a chassis dynamometer to determine emission factors and fuel consumption of three in-use Euro 4 vehicles, a gasoline-electric hybrid car, a bi-fuel gasoline/natural gas vehicle and a diesel car equipped with a particulate filter. Vehicles were tested on the New European Driving Cycle, a real urban driving cycle (Artemis Urban) and at constant speed (30, 70, $120 \mathrm{~km} / \mathrm{h}$ ).

The hybrid car emissions were remarkably influenced by cold start, with a ratio between cold and cold + hot 


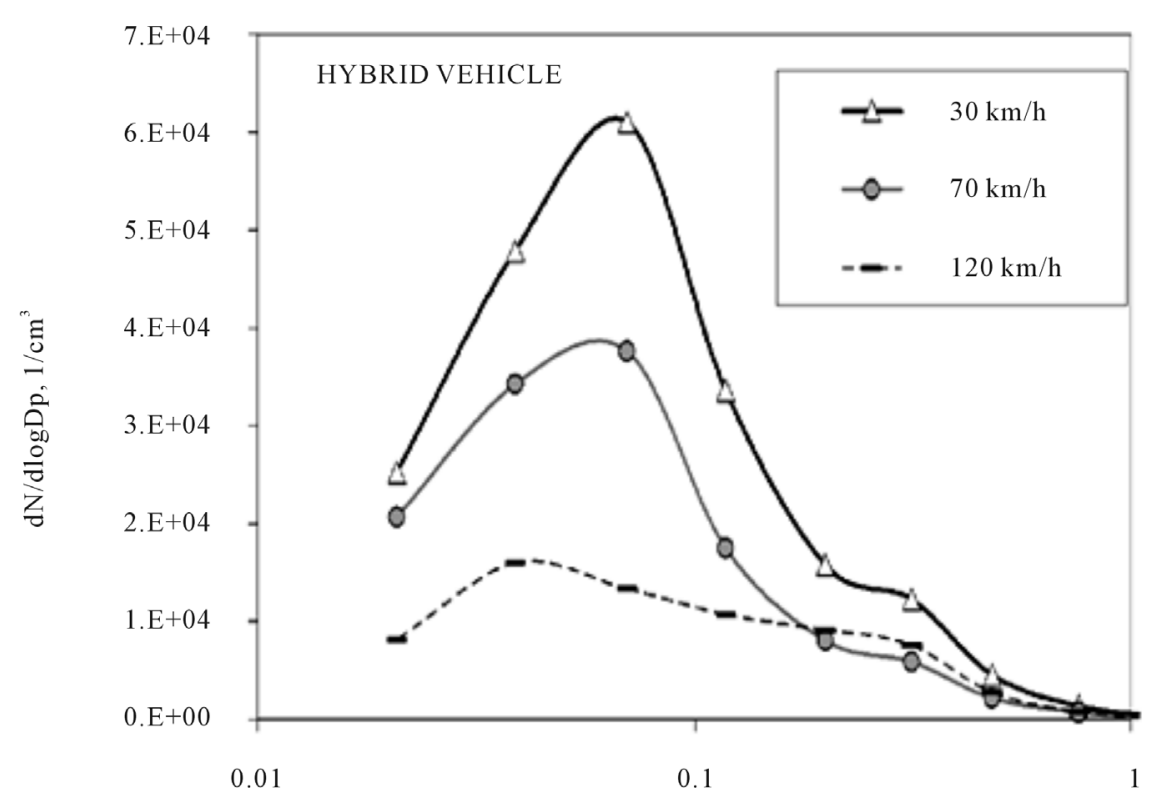

Aerodynamic diameter, $\mu \mathrm{m}$

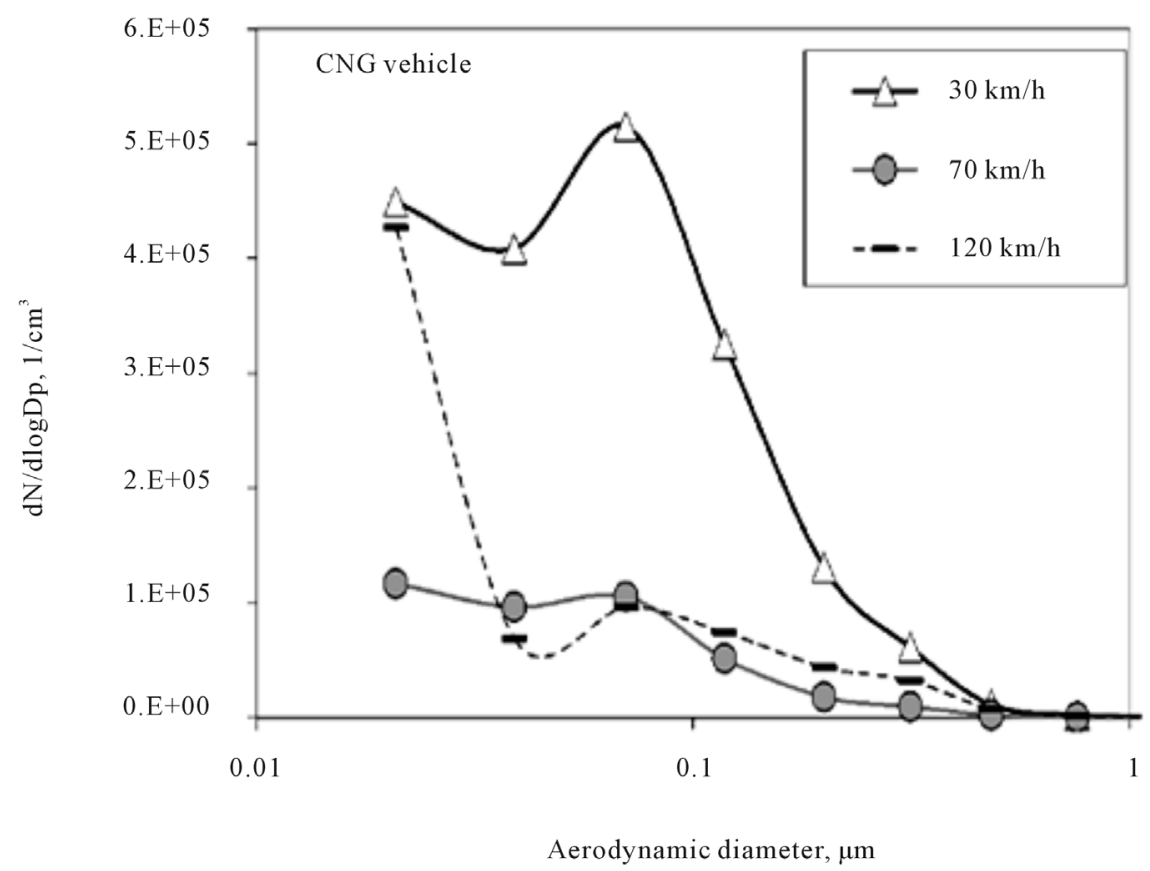

Figure 7. Particle size distributions in steady-state conditions.

emissions ranging from 64 to $99 \%$. Such result is caused by the strong effect of exhaust after-treatment devices once catalyst light-off temperature is reached and because the electric motor does not operate until the I.C. engine is warmed up. Experimental data show that, in hot condition, the internal combustion engine is switched off for about $45 \%$ of the Urban Driving Cycle duration, while during Artemis Urban cycle for $15 \%$ of the time. As a consequence of a lower time with the internal combustion engine switched off and the increase in time spent in transient conditions, fuel consumption over the Artemis Urban is higher than hot UDC. The hybrid vehicle, during constant speed tests, emits more particles at low speed. 

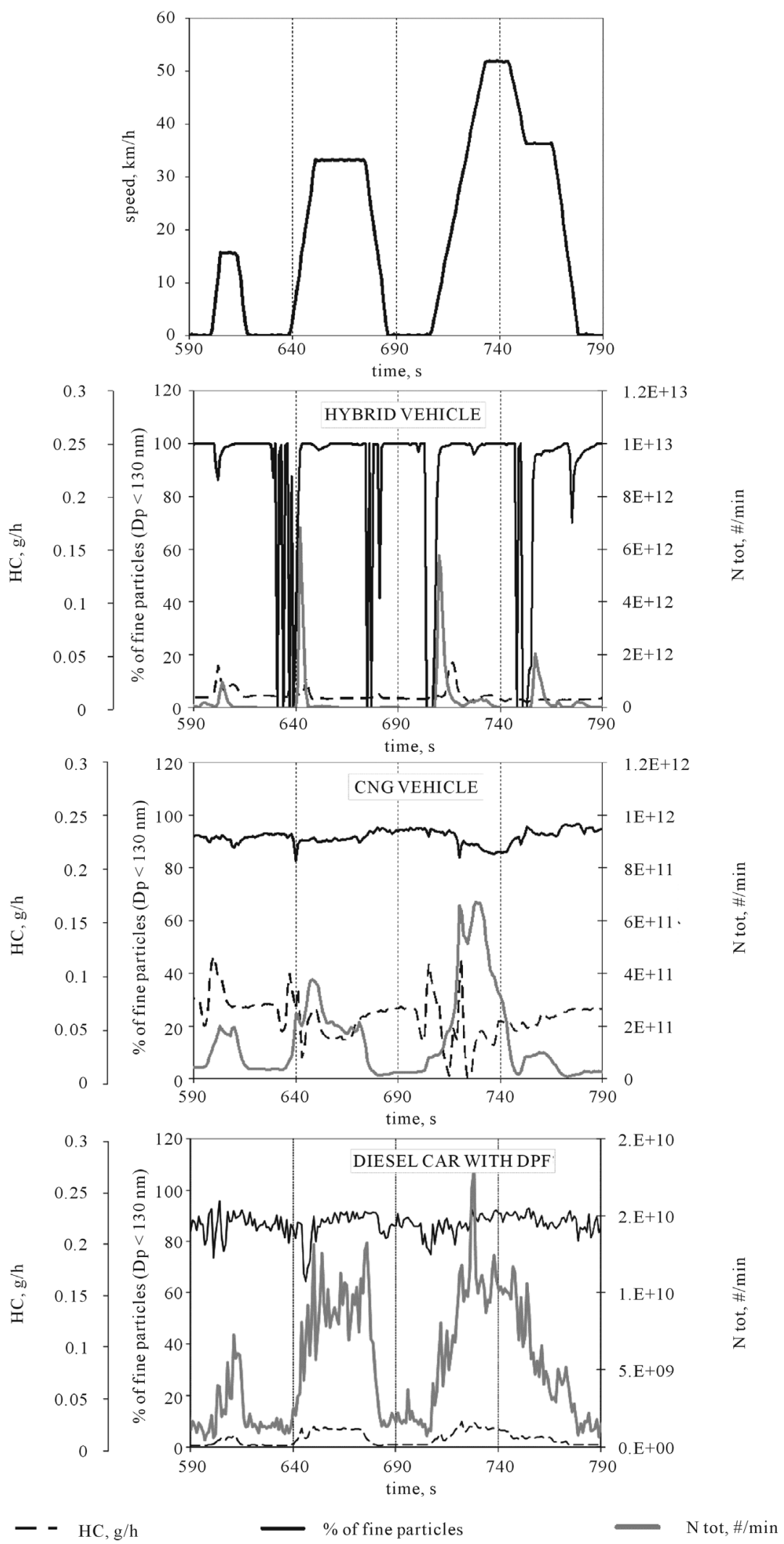

Figure 8. Contribution of fine particles to total particle number during the third UDC module with hybrid and CNG vehicles. 
The Natural Gas vehicle shows CO emissions exceeding Euro 4 limits, while HC and NOx emission factors comply with the Euro 5 ones. The effect of cold start on exhaust emissions is particularly evident for $\mathrm{CO}$ and HC, where the ratios between cold and cold + hot emissions are 93\% and 99\% respectively, while hot NOx emissions are higher than cold one. Fuel consumption and $\mathrm{CO}_{2}$ emissions on the Artemis Urban cycle resulted higher than those measured on type approval cycle. Particle number measurement at constant speed test shows particles nucleation mode, probably related to the sulphur content of CNG.

The diesel car slightly exceeds the Euro 4 limits as a consequence of high NOx emission. The ratios between UDC cold and UDC cold + hot emissions value are $98 \%$ and $75 \%$ for CO and HC respectively. PN emissions were low over the NEDC and Artemis Urban driving cycles due to the high trapping efficiency of the particulate filter.

The experimental campaign gave information on pollutant emissions of low-emitting vehicles. In particular the results are important for the CNG and the hybrid vehicles for which very few data are currently available.

It will be interesting to evaluate the emission behavior of these technologies over the new type-approval driving cycle WLTC (Table 2), that is more representative of real driving behavior.

\section{Acknowledgements}

This experimental work was partially carried out in the framework of a study funded by Italian Ministry of Transport.

\section{References}

[1] Gerlofs-Nijland, M.E., Campbell, A., Miller, M.R., David E Newby, D.E. and Cassee, F.R. (2009) Toxicity of Inhaled Traffic Related Particulate Matter. Journal of Physics, Conference Series, 151, 012049 (5pp). http://dx.doi.org/10.1088/1742-6596/151/1/012049

[2] Loomis, D., Grosse, Y., Lauby-Secretan, B., El Ghissassi, F., Bouvard, V., Benbrahim-Tallaa, L., Guha, N., Baan, R., Mattock, H. and Straif, K. (2013) The Carcinogenicity of Outdoor Air Pollution. The Lancet Oncology, 14, 1262-1263. http://dx.doi.org/10.1016/S1470-2045(13)70487-X

[3] European Parliament and Council (2007) Regulation (EC) No 715/2007 of the European Parliament and of the Council of 20 June 2007 on Type Approval of Motor Vehicles with Respect to Emissions from Light Passenger and Commercial Vehicles (Euro 5 and Euro 6) and on Access to Vehicle Repair and Maintenance Information. Official Journal of the European Union L 171, pp. 1-16.

[4] UNECE Regulation No.83/Add.82/Rev.4 (2011) Agreement Concerning the Adoption of Uniform Technical Prescriptions for Wheeled Vehicles, Equipment and parts Which Can Be Fitted and/or Be Used on Wheeled Vehicles and the Conditions for Reciprocal Recognition of Approvals Granted on the Basis of These Prescriptions. http://www.unece.org/fileadmin/DAM/trans/main/wp29/wp29regs/r083r4e.pdf

[5] Bergmann, M., Kirchner, U., Vogt, R. and Benter, T. (2009) On-Road and Laboratory Investigation of Low-Level PM Emissions of a Modern Diesel Particulate Filter Equipped Diesel Passenger Car. Atmospheric Environment, 43, 19081916. http://dx.doi.org/10.1016/j.atmosenv.2008.12.039

[6] Zarvalis, D., Tsakis, A., Konstandopoulos, A.G., Prati M.V. and Costagliola M.A. (2008) A Mobile Laboratory for On-Board and Ambient Level Emissions Measurement. SAE Vol. SP-2150 “Emissions Measurement \& Testing, 2008” SAE Paper 2008-01-0756. http://dx.doi.org/10.1016/j.scitotenv.2008.02.022

[7] Alvarez, R., Weilenmann, M. and Novak, P. (2008) Pollutant Emissions from Vehicles with Regenerating After-Treatment Systems in Regulatory and Real-World Driving Cycles. Science of the Total Environment, 398, 87-95.

[8] International Council on Clean Transportation-ICCT (2014) European Vehicle Market Statistics - Pocketbook 2014. http://www.theicct.org/sites/default/files/publications/EU_pocketbook_2014.pdf

[9] Fontaras, G., Pistikopoulos, P. and Samaras, Z. (2008) Experimental Evaluation of Hybrid Vehicle Fuel Economy AND Pollutant Emissions over Real-World Simulation Driving Cycles. Atmospheric Environment, 42, 4023-4035. http://dx.doi.org/10.1016/j.atmosenv.2008.01.053

[10] Zahabi, S.A.H., Miranda-Moreno, L., Barla, P. and Vincent, B. (2014) Fuel Economy of Hybrid-Electric versus Conventional Gasoline Vehicles in Real-World Conditions: A Case Study of Cold Cities in Quebec, Canada. Transportation Research Part D, 32, 184-192. http://dx.doi.org/10.1016/j.trd.2014.07.007

[11] Samaras, C. and Meisterling, K. (2008) Life Cycle Assessment of Greenhouse Gas Emissions from Plug-In Hybrid Vehicles: Implications for Policy. Environmental Science \& Technology, 42, 3170-3176.

http://dx.doi.org/10.1021/es702178s 
[12] Aslam, M.U., Masjuki, H.H., Kalam, M.A., Abdesselam, H., Mahlia, T.M.I. and Amalina, M.A. (2006) An Experimental Investigation of CNG as an Alternative Fuel for a Retrofitted Gasoline Vehicle. Fuel, 85, 717-724. http://dx.doi.org/10.1016/j.fuel.2005.09.004

[13] Turrio-Baldassarri, L., Battistelli, C.L., Conti, L., Crebelli, R., De Berardis, B., Iamiceli, A.L., Gambino, M. and Iannaccone, S. (2006) Evaluation of Emission Toxicity of Urban Bus Engines: Compressed Natural Gas and Comparison with Liquid Fuels. Science of the Total Environment, 355, 64-77. http://dx.doi.org/10.1016/j.scitotenv.2005.02.037

[14] Ristovski, Z., Morawska, L., Ayoko, G.A., Johnson, G., Gilbert, D. and Greenaway, C. (2004) Emissions from a Vehicle Fitted to Operate on Either Petrol or Compressed Natural Gas. Science of the Total Environment, 323, 179-194. http://dx.doi.org/10.1016/j.scitotenv.2003.10.023

[15] Verbeek, H.A. (2004) Vehicle Exhaust Emission Measuring on Four Fuels. Proceedings of the International Conference on Vehicles Alternative Fuel Systems \& Environmental Protection (VAFSEP), 6th-9th July 2004, Dublin City University, 86-91.

[16] Winkler, A., Dimopoulos, P., Hauert, R., Bach, C. and Aguirre, M. (2008) Catalytic Activity and Aging Phenomena of Three-Way Catalysts in a Compressed Natural Gas/Gasoline Powered Passenger Car. Applied Catalysis B: Environmental, 84, 162-169. http://dx.doi.org/10.1016/j.apcatb.2008.03.013

[17] Huai, T., Durbin, T.D., Rhee, S.H. and Norbeck, J.M. (2003) Investigation of Emission Rates of Ammonia, Nitrous Oxide and Other Exhaust Compounds from Alternative Fuel Vehicles Using a Chassis Dynamometer. International Journal of Automotive Technology, 4, 9-19.

[18] Andrè, M., Joumard, R., Vidona, R., Tassela, P. and Perret, P. (2006) Real-World European Driving Cycles, for Measuring Pollutant Emissions from High- and Low-Powered Cars. Atmospheric Environment, 40, 5944-5953. http://dx.doi.org/10.1016/j.atmosenv.2005.12.057

[19] Tutuianu, M., Marotta, A., Steven, H., Ericsson, E., Haniu, T., Ichikawa, N. and Ishii, H. (2013) Tecnical Report on Development of a World-Wide Worldwide Harmonized Light Duty Driving Test Cycle (WLTC). UN/ECE/WP.29/ GRPE/WLTP-IG DHC Subgroup. Informal Document GRPE-68-03 (68th GRPE, 7-10 January 2014).

[20] Weiss, M., Bonnel, P., Hummel, R., Provenza, A. and Manfredi, U. (2011) On-Road Emissions of Light-Duty Vehicles in Europe. Environmental Science \& Technology, 45, 8575-8581. http://dx.doi.org/10.1021/es2008424

[21] Schreiber, D., Forss, A.M., Mohr, M. and Dimopoulos, P. (2007) Particle Characterisation of Modern CNG, Gasoline and Diesel Passenger Cars. SAE Technical Paper 2007-24-0123.

[22] Conger, M.B. and Holmén, B.A. (2012) Real-World Engine Cold Start and “Restart” Particle Number Emissions from a 2010 Hybrid and Comparable Conventional Vehicle. TRB 91st Annual Meeting, Washington DC, 22-26 January 2012, Paper \#12-4570.

[23] Robinson, M. and Holmén, B.A. (2011) Onboard, Real-World Second-by-Second Particle Number Emissions from 2010 Hybrid and Comparable Conventional Vehicles. Transportation Research Record: Journal of the Transportation Research Board, 2233, 63-71. http://dx.doi.org/10.3141/2233-08

[24] Holmen, B.A. and Ayala, A. (2002) Ultrafine PM Emissions from Natural Gas, Oxidation-Catalyst Diesel, and Particle-Trap Diesel Heavy-Duty Transit Buses. Environmental Science \& Technology, 36, 5041-5050. http://dx.doi.org/10.1021/es015884g

[25] Novosel, D. (2013) Best Practice for Controlling Content of Oil, Water and Sulphur in CNG at Refuelling Station Level. Svenskt Gastekniskt Center AB (SGC) Rapport 2013:291. http://www.sgc.se/ckfinder/userfiles/files/SGC291.pdf

[26] del Álamo. J. (2013) NG/Biomethane Fuel Specification in Europe. CEN/TC 408. https://www2.unece.org/wiki/download/attachments/5802786/GFV\%2026-05e\%20rev\%201.pdf?api=v2

[27] Maricq, M.M., Podsiadlik, D.H. and Chase, R.E. (1999) Gasoline Vehicle Particle Size Distributions: Comparison of Steady State, FTP, and US06 Measurements. Environmental Science \& Technology, 33, 2007-2015. http://dx.doi.org/10.1021/es981005n

[28] Mamakos, A., Dardiotis, C. and Martini, G. (2012) Assessment of Particle Number Limits for Petrol Vehicles. European Commission-Joint Research Centre-Institute for Energy and Transport, Report EUR 25592 EN. 